\title{
Fluorescein Load Test: A New Diagnostic Test to Determine Location and Extension of Corneal Conjunctivalization in Partial and Total Limbal Stem Cells Deficiency
}

\author{
Maurizio Rolando $^{1}$ and Stefano Barabino ${ }^{2 *}$ \\ ${ }^{1}$ Ocular Surface and Dry Eye Clinic, ISPRE Ophthalmic, Genoa, Italy \\ ${ }^{2}$ Ocular Surface and Dry Eye Center, ASST Fatebenefratelli-Sacco, Sacco \\ Hospital- University of Milan, Milan, Italy \\ *Corresponding Author: Stefano Barabino, Ocular Surface and Dry Eye Center, \\ ASST Fatebenefratelli-Sacco, Sacco Hospital- University of Milan, Milan, Italy.
}

Received: February 22, 2021

Published: March 06, 2021

(C) All rights are reserved by Maurizio

Rolando and Stefano Barabino.

\begin{abstract}
Purpose: To evaluate the different fluorescein diffusion under the corneal epithelium and to compare its location and extension with the expression of cytokeratine (cK) 3 and cK 19 by epithelial cells of corneal surface.

Methods: Seventeen subjects with clinical signs of limbal failure participated in the examination. Fluorescein load test (FLT) was performed by instilling 1\% fluorescein every 10 seconds for 1 minute. Fluorescein diffusion under the corneal epithelium was observed with cobalt blue filter after 1 minute from the last instillation. Impression cytology samples were collected from corneal surfaces to observe the expression of specific corneal (cK 3) and conjunctival (cK 19) cytokeratines analysed by immunocytochemistry. The cK 3/cK 19 rate was compared with the extension and localization of FLT.

Results: Immunocytochemistry analysis discovered in the corneal surface the presence of cK 3 and cK 19. Samples with more than $80 \%$ of cK $3+$ cells were found in $70 \%$ of eyes with negative FLT. Furthermore, more than $50 \%$ of cells which expressed cK 19 in corneal epithelial samples were accompanied with $100 \%$ correlation between location of positive FLT and cK 19+ cells.

Conclusion: Since surgical approach is different in partial versus total limbal deficiency, it is important to recognize the localization and the extension of corneal conjunctivalization. The fluorescein load test is a simple diagnostic test to detect corneal area with limbal loss.
\end{abstract}

Keywords: Conjunctivalization; Fluorescein Staining; Corneal Stem Cells; Limbal Failure

\section{Introduction}

The ocular surface consists of two distinct types of epithelial layers, the conjunctival and the corneal epithelium. Although anatomically continuous with each other at the corneoscleral limbus, the two cell phenotypes represent quite distinct subpopulations [1]. Corneal epithelium is characterized by the presence of tight junctions and zonulae occludentes which greatly reduce its per- meability to water, and are responsible of the compact aspect of the multi layered epithelium [2]. The corneal epithelium exists in a state of dynamic equilibrium: while the terminally differentiated superficial cells are constantly shed into the tear pool, new young epithelial cells are distributed over the cornea supplied from limbal stem cells [1,3]. These cells are capable of proliferation, self-renewal, produce large number of terminally differentiated functional 
progeny and regenerate the tissue after injury [4-6]. Corneal stem cells reside at the corneo-scleral limbus in the palisades of Vogt and in the inter palisade network [7]. Limbal stem cells also act as a "barrier" to conjunctival epithelial cells and normally prevent them from migrating on to the corneal surface $[2,8]$. On the contrary, conjunctival epithelium lacks of impermeable structures and is characterized by higher water permeability than the corneal epithelium. The different behaviour in respect to water permeability of conjunctival epithelium compared to corneal epithelium is a factor that could be of help in assessing the epithelial cell phenotype in corneas with partial or total limbal loss [2].

Chemical and burn injuries, ultraviolet and ionizing radiation, Stevens-Johnson syndrome, advanced ocular cicatricial pemphigoid, multiple surgical procedures or cryotherapy to the limbal region, the chronic wearing of contact lenses and severe microbial keratitis can lead to aplasia or total loss of limbal stem cells owing to primary destruction. Moreover, other conditions such as aniridia and neurotrophic keratopathy can lead to hypofunction and gradual loss of stem cells $[9,10]$. Limbal stem cells may be partially or totally depleted, resulting in varying degrees of stem cell deficiency which results in defective epithelial covering of the cornea, and to conjunctiva epithelium invasion with vascularization, appearance of goblet cells and an irregular and unstable epithelium, a process which has been called conjunctivalization of the cornea [11-13]. The characteristic poor transparency and instability of epithelial cells, together with the presence of blood vessels are at the basis of the visual disturbances complained by patients affected by partial or total limbal stem cells loss. Abnormal corneal surfaces could be reconstructed by autograft or allograft transplantation of stem cell-containing limbal epithelium, a procedure called limbal transplantation [14].

Corneal conjunctivalization can be suspected at the slit-lamp examination by the presence of typical clinical pictures such as the presence of inflamed limbal area with a vascular pannus, or the grey aspect of the irregular and unstable epithelium, but the definitive diagnosis of limbal stem cell deficiency can be assessed only by sampling the suspected epithelium for defining its phenotype. This procedure is based on impression cytology sampling of the ocular surface epithelia and the analysis of the expression of specific cytokeratins (cK) by corneal and conjunctival epithelial cells [15]. Corneal immunophenotype was described cK 3+/cK 19- and con- junctival immunophenotype as cK 3-/cK 19+ by Kruse., et al. [12]. In order to obtain the best outcome for the surgery, from a clinical point of view, it is important to recognize and locate the areas of corneal conjunctivalization in order to spare the surviving corneal epithelium and remove all the conjunctival cells during the surgical manoeuvres.

Based on the different water permeability of the corneal and conjunctival epithelium [2] our hypothesis is that recognition of location and extension of corneal conjunctivalization after partial or total limbal stem cells deficiency would be able to be identified by using fluorescein, a well known water soluble vital stain.

\section{Materials and Methods}

Seventeen eyes of 17 consecutive patients ( 8 female, mean age: $46 \pm 17$ years) with clinical signs of total or partial limbal failure participated in the study at Clinica Oculistica, IRCCS Azienda Ospedaliera Universitaria San Martino-IST, Genoa, Italy. All the patients obtained a detailed explanation of all procedures and signed a written informed consent before being included into the study. The research adhered to the tenets of the Declaration of Helsinki.

\section{Clinical examination}

All patients underwent a slit lamp examination to observe and grade clinical signs of limbal failure followed by some degree of corneal epithelium conjunctivalization and clinical symptoms. Baseline characteristics of enrolled patients including age, etiology and the type of limbal failure are summarized in table 1 . Limbal failure was observed as partial in 9 patients, total in 5 patients and uncertain in 3 patients. All the patients showed unilateral involvement, except patients with Steven-Johnson syndrome, aniridia, and pemphigoid in whom only the right eye was considered for the study.

\section{Fluorescein load test (FLT)}

Fluorescein load test was performed without using topical anaesthetics. Fifty microliters of $1 \%$ fluorescein solution were instilled by a micropipette in the study eye every 10 seconds for 1 minute, while patients were free to blink. Fluorescein diffusion under corneal epithelium was observed after 1 minute in the four quadrants: nasal, temporal, superior and inferior by slit lamp biomicroscopy with cobalt blue light filter. An additional yellow filter (Kodak Wratten) was applied in front of the objective of the slit 


\begin{tabular}{|c|c|c|c|}
\hline Identifier & Age & $\begin{array}{l}\text { Presumed etiology } \\
\text { of limbal stem cell } \\
\text { deficiency }\end{array}$ & $\begin{array}{l}\text { Type of } \\
\text { limbal } \\
\text { failure }\end{array}$ \\
\hline 1 & 29 & Contact lens wearing & $\mathrm{P}$ \\
\hline 2 & 37 & Alkali burning & $\mathrm{U}$ \\
\hline 3 & 66 & Pemphigoid & $\mathrm{T}$ \\
\hline 4 & 31 & Contact lens wearing & $\mathrm{P}$ \\
\hline 5 & 53 & Alkali burning & $\mathrm{U}$ \\
\hline 6 & 62 & Chronic inflammation & $\mathrm{P}$ \\
\hline 7 & 24 & Surgery of pterygium & $\mathrm{P}$ \\
\hline 8 & 55 & Alkali burning & $\mathrm{P}$ \\
\hline 9 & 70 & Alkali burning & $\mathrm{T}$ \\
\hline 10 & 49 & $\begin{array}{l}\text { Stevens johnson } \\
\text { syndrome }\end{array}$ & $\mathrm{T}$ \\
\hline 11 & 41 & Contact lens wearing & $\mathrm{P}$ \\
\hline 12 & 12 & Aniridia & $\mathrm{T}$ \\
\hline 13 & 49 & Alkali burning & $\mathrm{U}$ \\
\hline 14 & 32 & Surgery of pterygium & $\mathrm{P}$ \\
\hline 15 & 60 & Chemical burning & $\mathrm{P}$ \\
\hline 16 & 71 & Pemphigoid & $\mathrm{T}$ \\
\hline 17 & 39 & Alkali burning & $\mathrm{P}$ \\
\hline
\end{tabular}

Table 1: Summary of age, presumed etiology of the limbal failure, and the type of limbal loss of all the seventeen patients included in the study. The mean age was $46 \pm 17$ years. Type of the limbal loss was described as partial (P), total (T) and uncertain (U) in 9, 5 and 3 cases respectively.

lamp for a better definition of the spreading of fluorescein under the corneal epithelium. Fluorescein diffusion under the conjunctivalized corneal epithelium, fluorescein staining of the epithelial defects and fluorescein pooling of the irregular surface were also differentiated. FLT was considered positive for a corneal area if fluorescein diffusion under the epithelium was able to be detected. Fluorescein loading was observed by the same investigator in all cases.

\section{Impression cytology}

After administration of topical anesthesia with $0.04 \%$ oxybuprocaine, impression cytology was performed on all the involved eyes at least 30 minutes after the instillation of the last staining eye drop to avoid any possible interference with immunohistochemistry analysis. Four separate strips of cellulose-acetate filter paper (Supor 200 Membrane Disc Filters, pore size: 0.2 micron, diameter $13 \mathrm{~mm}$, Pall Corporation, USA) were applied on superior, inferior, nasal and temporal part of the cornea, pressed gently and then removed. All the samples were immediately fixed with Spray-cite fixative, transferred to glass slides, a drop of acetone was added, and after complete dry they were transferred for laboratory evaluation.

\section{Immunocytochemistry}

The procedure described by Krenzer and Freddo [16] was used to detect cytokine expression. Two sets of antibodies and corresponding negative controls were used for assaying cK 3/cK 19 percent concentration in the corneal samples. The primary antibodies were respectively Cytokeratin 3/2p (AE5): sc-80000 (Santa Cruz Biotechnology) specific of corneal epithelial cells, and monoclonal anti-cytokeratin 4.62 (Sigma) specific of conjunctival epithelial cells. ImmunoCruz sc-2050 (Santa Cruz Biotechnology) was used as the secondary antibody for all the assays. Antibodies were used in a 1:100 dilution. CK3 and cK19+ cells in corneal samples, and cK3/cK19 cells ratio were evaluated.

\section{Results}

Fluorescein load test confirmed the type of limbal failure observed clinically (Table 2). In fact we obtained in 5 patients with presumed, clinically evident, total limbal loss a positive FLT in all the corneal areas, while in patients with partial limbal loss we found a positive FLT only in some parts of the cornea. Fluorescein diffusion under the corneal epithelial surface was detected in all 9 cases of partial limbal deficiency in correspondence of the localization of limbal cells loss. Furthermore, in 3 cases of uncertain limbal failure, fluorescein diffusion was able to show the limbal deficiency as total in 1 case and as partial in the other 2 cases.

The $\mathrm{cK} 3 / \mathrm{cK} 19$ ratio was determined in every case to evaluate the diffusion of conjunctivalization (Table 3). In all patients with partial and total limbal loss clinically diagnosed, immunocytochemistry has shown in the corneal area a greater presence of cytokeratines typical of the conjunctiva (cK 19) than cytokeratines typical of the cornea (ck 3). Also, in all 3 patients with uncertain clinical diagnosis of limbal loss we recorded a greater percentage of cK19+ cells. 
Fluorescein Load Test: A New Diagnostic Test to Determine Location and Extension of Corneal Conjunctivalization in Partial and Total Limbal Stem Cells Deficiency

\begin{tabular}{|l|c|c|c|c|c|}
\hline \multirow{2}{*}{$\begin{array}{l}\text { Patient } \\
\text { No }\end{array}$} & \multicolumn{4}{|c|}{ Fluorescein Load Test (FLT) } & $\begin{array}{c}\text { Type of } \\
\text { limbal failure } \\
\text { observed } \\
\text { clinically }\end{array}$ \\
\cline { 2 - 6 } & Superior & Nasal & Inferior & Temporal & In all cornea \\
\hline 1 & P & N & N & P & P \\
\hline 2 & N & P & P & P & U \\
\hline 3 & P & P & P & P & T \\
\hline 4 & P & P & N & P & P \\
\hline 5 & P & P & P & P & U \\
\hline 6 & N & P & P & N & P \\
\hline 7 & N & P & N & N & P \\
\hline 8 & N & N & P & P & P \\
\hline 9 & P & P & P & P & T \\
\hline 10 & P & P & P & P & T \\
\hline 11 & P & P & N & N & P \\
\hline 12 & P & P & P & P & T \\
\hline 13 & P & P & P & N & U \\
\hline 14 & N & P & N & N & P \\
\hline 15 & P & P & N & N & P \\
\hline 16 & P & P & P & P & T \\
\hline 17 & N & P & P & P & P \\
\hline
\end{tabular}

Table 2: Type of the limbal loss was described as partial (P), total (T) and uncertain (U) during clinical examination with slit lamp.

Fluorescein load test (FLT) confirmed the type of partial or total limbal failure observed clinically and revealed the type of uncertain limbal loss. We obtained, in patients with total limbal loss, a positive FLT in all the corneal areas; while in the patients with partial limbal loss we found a positive FLL only in some parts of the cornea. In partial limbal deficiency cases, FLT was able to detect the exact localization of limbal cells loss.

CK3+ epithelial cells results and areas of negative FLT are compared in figure 1 . We found less than $80 \%$ of cK3+ cells in the samples of $29 \%$ FLT negative eyes, and more than $80 \%$ of cK3 + cells in the samples of $71 \%$ FLT negative eyes.

CK19 expression in corneal epithelial samples and areas of positive FLT are compared in figure 2. We did not find areas of positive FLT with less than $30 \%$ of cK19+ cells in the samples. We observed areas of positive FLT in $92.3 \%$ of the eyes if the cK19+ cells were more than $30 \%$.

\section{Discussion and Conclusion}

In our study we demonstrated for the first time that the fluorescein load test could be used to identify corneal damage related to limbal stem cells deficiency in everyday practice. To date, there are no diagnostic tests available to identify corneal epithelial stem cells defects, and the laboratory techniques are indirect [8]. Direct markers for stem cells have not been established, but there is clinical and experimental evidence supporting the location of corneal epithelial stem cells mainly at the limbal region $[7,8,12,17]$.

Early studies supported the concept that normal epithelium is maintained by the surrounding conjunctival epithelium. This assumption was described by the term "conjunctival transdifferentiation" $[10,18]$. However, there are several evidence against the above assumption and favour the idea that "the corneal and conjunctival epithelia are not equipotent" but they can be considered as progenitors of two different phenotypes of epithelial cells with a distinct location on the ocular surface $[1,19,20,21]$. Just as corneal epithelial wounds heal in a centripetal manner from the limbus $[10,22]$, conjunctival epithelial wounds heal in a centripetal manner from the fornix [23].

Davanger and Evensen in 1971, for the first time, introduced the idea that the renewal of corneal epithelium is allowed by epithelial cells present in the limbal area [24]. They observed how the epithelial cells migrate from the limbal region toward the central cornea and moreover they suggested that the palisades of Vogt serve as a generative organ for corneal epithelial cells. The exact location of the stem cells of corneal epithelium was unclear until Schermer., et al. showed the absence of a differentiation marker, a $64-\mathrm{kD}$ corneal epithelial keratin, in the limbal basal cells. They suggested the sclero-corneal limbus as the origin of cell proliferation, self-renewal and migration after a corneal epithelial defect [8]. However Dua and co-workers stated - based on in vivo observation of central corneal epithelium after total limbal deficiency with in vivo confocal microscopy - that the basal transient amplifying cells of the central surviving epithelium are independently capable of maintaining the overlying cell mass for a long period of time, suggesting that the limbus may not have a critical role in physiologic corneal epithelial homeostasis [25].

In order to select the proper surgical approach, knowledge of the exact location of corneal conjunctivalization is mandatory. The 
Fluorescein Load Test: A New Diagnostic Test to Determine Location and Extension of Corneal Conjunctivalization in Partial and Total Limbal Stem Cells Deficiency

\begin{tabular}{|c|c|c|c|c|c|c|c|c|}
\hline \multirow{2}{*}{$\begin{array}{c}\text { Patient } \\
\text { No }\end{array}$} & \multicolumn{4}{|c|}{ cK 3/cK 19 rate determined by immunohistochemistry } & \multicolumn{4}{|c|}{ Fluorescein Load Test } \\
\hline & Superior & Nasal & Inferior & Temporal & Superior & Nasal & Inferior & Temporal \\
\hline 1 & $15 / 75$ & $30 / 45$ & $85 / 10$ & $30 / 55$ & $\mathrm{P}$ & $\mathrm{N}$ & $\mathrm{N}$ & $\mathrm{P}$ \\
\hline 2 & $80 / 20$ & $25 / 50$ & $5 / 80$ & $45 / 45$ & $\mathrm{~N}$ & $\mathrm{P}$ & $\mathrm{P}$ & $\mathrm{P}$ \\
\hline 3 & $10 / 90$ & $10 / 80$ & $10 / 95$ & $10 / 85$ & $\mathrm{P}$ & $P$ & $\mathrm{P}$ & $\mathrm{P}$ \\
\hline 4 & $15 / 60$ & $55 / 40$ & $50 / 10$ & $60 / 40$ & $\mathrm{P}$ & $\mathrm{P}$ & $\mathrm{N}$ & $\mathrm{P}$ \\
\hline 5 & $20 / 80$ & $10 / 80$ & $25 / 60$ & $10 / 70$ & $\mathrm{P}$ & $\mathrm{P}$ & $\mathrm{P}$ & $\mathrm{P}$ \\
\hline 6 & $70 / 30$ & $30 / 70$ & $10 / 80$ & $40 / 50$ & $\mathrm{~N}$ & $\mathrm{P}$ & $\mathrm{P}$ & $\mathrm{N}$ \\
\hline 7 & $60 / 20$ & $50 / 80$ & $80 / 10$ & $90 / 00$ & $\mathrm{~N}$ & $\mathrm{P}$ & $\mathrm{N}$ & $\mathrm{N}$ \\
\hline 8 & $85 / 25$ & $80 / 30$ & $10 / 90$ & $35 / 55$ & $\mathrm{~N}$ & $\mathrm{~N}$ & $\mathrm{P}$ & $\mathrm{P}$ \\
\hline 9 & $25 / 70$ & $15 / 65$ & $10 / 85$ & $20 / 95$ & $\mathrm{P}$ & $\mathrm{P}$ & $\mathrm{P}$ & $\mathrm{P}$ \\
\hline 10 & $10 / 70$ & $20 / 80$ & $10 / 90$ & $20 / 90$ & $\mathrm{P}$ & $\mathrm{P}$ & $\mathrm{P}$ & $\mathrm{P}$ \\
\hline 11 & $40 / 60$ & $45 / 55$ & $80 / 30$ & $40 / 40$ & $\mathrm{P}$ & $\mathrm{P}$ & $\mathrm{N}$ & $\mathrm{N}$ \\
\hline 12 & $20 / 70$ & $30 / 65$ & $15 / 70$ & $25 / 45$ & $\mathrm{P}$ & $\mathrm{P}$ & $\mathrm{P}$ & $\mathrm{P}$ \\
\hline 13 & $30 / 85$ & $40 / 70$ & $25 / 90$ & $40 / 35$ & $\mathrm{P}$ & $\mathrm{P}$ & $\mathrm{P}$ & $\mathrm{N}$ \\
\hline 14 & $65 / 45$ & $20 / 70$ & $60 / 30$ & $90 / 00$ & $\mathrm{~N}$ & $\mathrm{P}$ & $\mathrm{N}$ & $\mathrm{N}$ \\
\hline 15 & $60 / 50$ & $40 / 70$ & $40 / 40$ & $30 / 40$ & $\mathrm{P}$ & $P$ & $\mathrm{~N}$ & $\mathrm{~N}$ \\
\hline 16 & $10 / 70$ & $20 / 85$ & $0 / 80$ & $20 / 90$ & $\mathrm{P}$ & $\mathrm{P}$ & $\mathrm{P}$ & $\mathrm{P}$ \\
\hline 17 & $30 / 40$ & $25 / 70$ & $50 / 40$ & $25 / 60$ & $\mathrm{~N}$ & $\mathrm{P}$ & $\mathrm{P}$ & $\mathrm{P}$ \\
\hline
\end{tabular}

Table 3: The cK 3/cK 19 concentration ratio in the corneal epithelial samples and the results of the fluorescein load test in four different localizations ( $\mathrm{P}=$ positive, $\mathrm{N}=$ negative fluorescein load test). Both immunohistochemistry and FLT were performed on 4 corneal areas (superior, nasal, inferior, temporal).

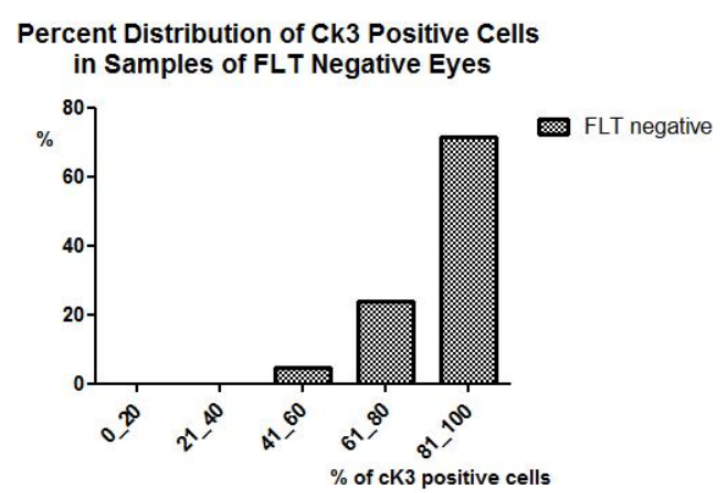

Figure 1: Less than $80 \%$ of CK3 positive cells were found in the samples with FLT negative in $29 \%$ of eyes and more than $80 \%$ of CK3 positive cells in the sample with FLT negative in remaining $71 \%$ of eyes.

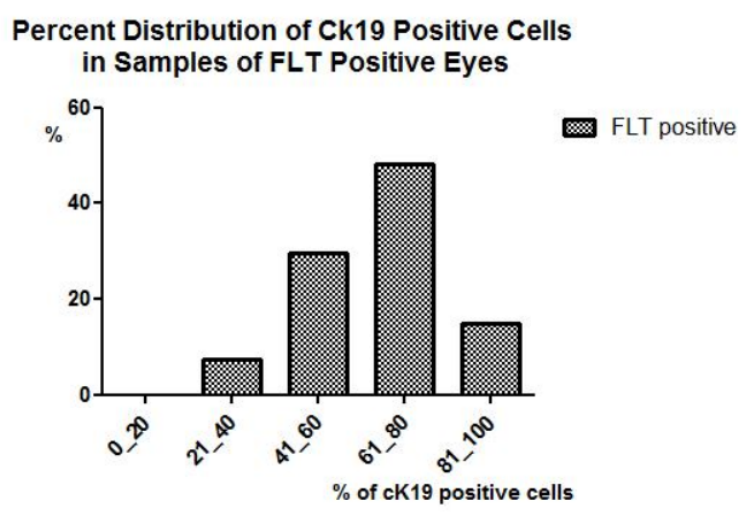

Figure 2: We did not find areas of positive FLT when there are less than $30 \%$ of CK19 positive cells in the sample. We observed areas of positive FLT in $92.31 \%$ of the eyes if the CK19 positive cells are more than $30 \%$, instead if they are more than $50 \%$ we found areas of positive FLT in $100 \%$ of the eyes. 
detection of goblet cells after impression cytology of the corneal epithelium by periodic acid-Schiff staining has been used to diagnose limbal stem cells deficiency cases, but recently Sacchetti., et al. demonstrated that the absence of goblet cells within the corneal epithelium does not exclude the diagnosis of limbal stem cells deficiency [26]. Donisi., et al. provided global information about the percentage of conjunctival cells present on the cornea in cases of ocular surface diseases by using cK3 and cK 19, but they have not specified the exact location of such metaplastic changes [15]. In fact different localization of the same extension of the conjunctival epithelium on the cornea may suggest different surgical approaches [27-29]. The exact location and extent of limbal damage is necessary to reach the better outcome of corneal transplantation because stem cell integrity avoids corneal conjunctivalization, vascularization and chronic inflammation, thus allowing normal epithelial resurfacing and good visual results. Patients with limbal deficiency are generally poor candidates for conventional corneal transplantation, where limbal stem cells are not part of the graft, because the pre-existing corneal vascularization and inflammation increases the risk of allograft rejection. Moreover they tend to undergo recurrent conjunctivalization owing to the loss of stem cell function [30].

Fluorescein load test for detecting corneal epithelium disease was described for the first time by Caffery and Josephson in 1991. They described the fluorescein load test as a simple, non-invasive and non-traumatic method for examining the ocular surface, especially the corneal area, in 6 patients who were followed for 4 weeks in order to study corneal fluorescein staining changes on a daily basis [31].

In our present study we modified the number of fluorescein instillations and we focused on the corneal fluorescein load and its relationship with cK3 and $\mathrm{cK} 19$ cells expression, confirming that FLT is a simple, non-invasive technique and relatively easy to perform, and that this method can be used to improve the localization of corneal conjunctivalization and also to follow changes in corneal ocular surface over time.

In conclusion the fluorescein load test yields reliable information about the area sampled with minimal discomfort to the patient. In fact the conjunctival epithelial ingrowth on a cornea with limbal loss, can quickly and easily be detected because of is higher water permeability compared to corneal epithelium. This tech- nique should be developed and introduced in clinical practice to recognize corneal damage and to individualize the most accurate surgical approach to partial and total limbal deficiency.

\section{Acknowledgments}

The author has no conflicts of interest to declare.

\section{Conflicts of Interest}

The authors report no conflict of interest.

\section{Bibliography}

1. Dua HS and Azuara-Blanco A. "Limbal stem cells of the corneal epithelium". Survey of Ophthalmology 44 (2000): 415-425.

2. Huang AJ., et al. "Paracellular permeability of corneal and conjunctival epithelia". Investigative Ophthalmology and Visual Science 30 (1989): 684-689.

3. Zieske JD. "Perpetuation of stem cells in the eye". Eye 8 (1994): 163-169.

4. Sridhar MS., et al. "Impression cytology proven corneal stem cell deficiency in patients after surgeries involving the limbus". Cornea 20 (2001): 145-148.

5. Chen JJY and Tseng SCG. "Corneal epithelial wound healing in partial limbal deficiency". Investigative Ophthalmology and Visual Science 31 (1990): 1301-14.

6. Dua HS., et al. "Corneal epithelial wound healing". British Journal of Ophthalmology 78 (1994): 401-408.

7. Tseng SC and Tsai RJ. "Limbal transplantation for ocular surface reconstruction-a review". Fortschr Ophthalmology 88 (1991): 236-242.

8. Schermer A., et al. "Differentiation-related expression of a major $64 \mathrm{~K}$ corneal keratin in vivo and in culture suggests limbal location of corneal epithelial stem cells". Journal of Cell Biology 103 (1986): 49-62.

9. Puangsricharern V and Tseng SCG. "Cytologic evidence of corneal diseases with limbal stem cell deficiency". Ophthalmology 102 (1995): 1476-1485.

10. Shapiro MS., et al. "Corneal re-epithelialization from the conjunctiva". Investigative Ophthalmology and Visual Science 21 (1981): 135-142. 
11. Tseng SC., et al. "Goblet cell density and vascularization during conjunctival transdifferentiation". Investigative Ophthalmology and Visual Science 25 (1984): 1168-1176.

12. Kruse FE., et al. "Conjunctival transdifferentiation is due to the incomplete removal of limbal basal epithelium". Investigative Ophthalmology and Visual Science 31 (1990): 1903-1913.

13. Huang AJW and Tseng SCG. "Corneal epithelial wound healing in the absence of limbal epithelium". Investigative Ophthalmology and Visual Science 32 (1991): 96-105.

14. Tsai SF., et al. "Comparsion of limbal and conjunctival autograft transplantation for corneal surface reconstruction in rabbits". Ophthalmology 97 (1990): 446-455.

15. Donisi PM., et al. "Analysis of limbal stem cell deficiency by corneal impression cytology". Cornea 22 (2000): 533-538.

16. Krenzer KL and Freddo TF. "Cytokeratin expression in normal human bulbar conjunctiva obtained by impression cytology". Investigative Ophthalmology and Visual Science 38 (1997): 142152.

17. Chee KY., et al. "Limbal stem cells: the search for a marker". Clinical and Experimental Ophthalmology 34 (2006): 64-73.

18. Kinoshita S., et al. "Limbal epithelium in ocular surface wound healing". Investigative Ophthalmology and Visual Science 23 (1982): 73-80.

19. Hall PA and Watt FM. "Stem cells: the generation and maintenance of cellular diversity". Development 106 (1989): 619-633.

20. Chen WY., et al. "Conjunctival epithelial cells do not transdifferentiate inorganotypic cultures: expression of K12 keratin is restricted to corneal epithelium". Current Eye Research 13 (1994): 765-778.

21. Moyer PD., et al. "Conjunctival epithelial cells can resurface denuded cornea, but do not transdifferentiate to express corneaspecific keratin 12 following removal of limbal epithelium in mouse". Differentiation 60 (1996): 31-38.

22. Dua HS and Forrester JV. "Clinical patterns of corneal epithelial wound healing". American Journal of Ophthalmology 104 (1987): 481-459.
23. Dua HS. "The conjunctiva in corneal epithelial wound healing". British Journal of Ophthalmology 82 (1998): 1407-1411.

24. Davanger M and Evensen A. "Role of the pericorneal papillary structure in renewal of corneal epithelium". Nature 229 (1971): 560-561.

25. Dua HS., et al. "The role of limbal stem cells in corneal epithelial maintenance: testing the dogma". Ophthalmology 116 (2009): 856-873.

26. Sacchetti M., et al. "Clinical and cytological findings in limbal stem cell deficiency". Graefe's Archive for Clinical and Experimental Ophthalmology 243 (2005): 870-876.

27. Grüterich M and Tseng SC. "Surgical approaches for limbal stem cell deficiency". Klinische Monatsblatter fur Augenheilkunde 219 (2002): 333-339.

28. Kruse FE and Reinhard T. "Limbus transplantation for reconstruction of the ocular surface". Ophthalmologe 98 (2001): 818-831.

29. Holland EJ and Schwartz GS. "The evolution of epithelial transplantation for severe ocular surface disease and a proposed classification system". Cornea 15 (1996): 549-556.

30. Sangwan VS. "Limbal stem cells in health and disease". Bioscience Report 21 (2001): 385-405.

31. Caffery BE and Josephson JE. "Corneal staining after sequential instillations of fluorescein over 30 days". Optometry and Vision Science 68 (1991): 467-469.

\section{Assets from publication with us}

- Prompt Acknowledgement after receiving the article

- Thorough Double blinded peer review

- Rapid Publication

- Issue of Publication Certificate

- High visibility of your Published work

Website: www.actascientific.com/

Submit Article: www.actascientific.com/submission.php Email us: editor@actascientific.com

Contact us: +919182824667 